\title{
Comparative efficacy of two next-generation Rift Valley fever vaccines
}

\author{
J. Kortekaas a,*, N. Oreshkova a,b, L. van Keulen ${ }^{a}$, J. Kant ${ }^{a}$, B.J. Bosch ${ }^{b}$, M. Bouloy ${ }^{c}$, \\ V. Moulin ${ }^{\mathrm{d}}$, D. Goovaerts ${ }^{\mathrm{d}, 1}$, R.J.M. Moormann ${ }^{\mathrm{a}, \mathrm{b}}$ \\ ${ }^{a}$ Department of Virology, Central Veterinary Institute of Wageningen University and Research Centre (CVI-WUR), P. O. Box 65, 8200 AB Lelystad, \\ The Netherlands \\ ${ }^{\mathrm{b}}$ Department of Infectious Diseases and Immunology, Virology Division, Faculty of Veterinary Medicine, Utrecht University, Yalelaan 1, 3584 CL, Utrecht, \\ The Netherlands \\ ' Institut Pasteur, Unité de Génétique Moléculaire des Bunyavirus, 75724 Paris Cedex 15, France \\ ${ }^{\mathrm{d}}$ Intervet International BV/Merck Sharp and Dohme (MSD) Animal Health, Wim de Körverstraat 35, 5831 AN Boxmeer, The Netherlands
}

\section{A R T I C L E I N F O}

\section{Article history:}

Received 6 May 2014

Received in revised form 11 June 2014

Accepted 9 July 2014

Available online 19 July 2014

\section{Keywords:}

Vaccine

Rift Valley fever virus

Comparative

Sheep

Nonspreading

Replicon

R566

Clone 13

NSR-Gn

\begin{abstract}
A B S T R A C T
Rift Valley fever virus (RVFV) is a re-emerging zoonotic bunyavirus of the genus Phlebovirus. A natural isolate containing a large attenuating deletion in the small (S) genome segment previously yielded a highly effective vaccine virus, named Clone 13. The deletion in the S segment abrogates expression of the NSs protein, which is the major virulence factor of the virus. To develop a vaccine of even higher safety, a virus named R566 was created by natural laboratory reassortment. The R566 virus combines the S segment of the Clone 13 virus with additional attenuating mutations on the other two genome segments $\mathrm{M}$ and $\mathrm{L}$, derived from the previously created MP-12 vaccine virus. To achieve the same objective, a nonspreading RVFV (NSR-Gn) was created by reverse-genetics, which not only lacks the NSs gene but also the complete $M$ genome segment. We have now compared the vaccine efficacies of these two next-generation vaccines and included the Clone 13 vaccine as a control for optimal efficacy. Groups of eight lambs were vaccinated once and challenged three weeks later. All mock-vaccinated lambs developed high fever and viremia and three lambs did not survive the infection. As expected, lambs vaccinated with Clone 13 were protected from viremia and clinical signs. Two lambs vaccinated with R566 developed mild fever after challenge infection, which was associated with low levels of viral RNA in the blood, whereas vaccination with the NSR-Gn vaccine completely prevented viremia and clinical signs.
\end{abstract}

(c) 2014 Elsevier Ltd. All rights reserved.

\section{Introduction}

Rift Valley fever virus (RVFV) is a mosquito-borne Phlebovirus of the Bunyaviridae family that causes recurrent outbreaks among ruminants, particularly sheep. The virus is endemic to the African continent, the Arabian Peninsula and several islands off the eastern coast of southern Africa. Abortion storms and high mortalities among newborn animals are characteristic features of RVFV outbreaks, although losses among adult animals can also be considerable. Transmission of the virus among ruminants occurs via mosquito vectors, whereas humans can be infected via either mosquito bite or via contact with bodily fluids released during

\footnotetext{
* Corresponding author at: Virology Division, Central Veterinary Institute of Wageningen University Research Centre, Edelhertweg 15, 8219 PH Lelystad, The Netherlands. Tel.: +31 320 238198; fax: +31 320238225 .

E-mail addresses: jeroen.kortekaas@wur.nl (J. Kortekaas), DannyGoovaerts@skynet.be (D. Goovaerts).

1 Present address: DGVAC Consultancy, Langenberg 3, 2460 Lichtaart, Belgium.
}

the slaughtering of diseased animals. Infections in humans generally manifest as mild, transient disease, but a small percentage of patients develop serious complications, such as ocular impediments, hemorrhagic fever or encephalitis. Considering the zoonotic nature of RVFV, vaccination of livestock will benefit both animal and human health [1].

The first veterinary RVFV vaccine was developed by Smithburn in 1949 [2]. After serial intracerebral passage in mice, a mutant virus was isolated with strongly reduced hepatotropism. Although the resulting Smithburn strain is attenuated, its residual virulence is well recognized $[3,4]$. To create a virus with a more attenuated profile, Caplen and co-workers cultivated the virulent RVFV strain ZH548, isolated during the Egyptian outbreak of 1977, in the presence of the mutagen 5-fluorouracil [5]. This procedure yielded the mutagenized MP-12 strain which was derived from the parental virulent strain after 12 successive passages in the presence of the mutagen. Later studies demonstrated that the MP-12 virus contains attenuating mutations in each of the three genome segments [6].

The safety and efficacy of MP-12 were evaluated in several extensive animal trials. These experiments suggested that the 
vaccine can be safely applied in lambs, calves and ewes after the first trimester of gestation [7-11]. In a recent study, vaccination of ewes during the first trimester of gestation with either MP-12 or a corresponding recombinant virus did not cause untoward effects in the ewes, although one of four ewes of each group was found to carry a dead fetus at the end of the experiment [9]. However, it has remained unclear whether these fetal mortalities were caused by the vaccine viruses. Nevertheless, efforts are continuing to further attenuate the MP-12 virus by reverse-genetics $[9,12]$.

In 1995, a natural nonpathogenic RVFV isolate was described, named Clone 13, which contains a large (70\%) internal deletion in the NSs gene of the small (S) genome segment [13]. Studies on the Clone 13 virus demonstrated that the NSs protein suppresses type-I interferon induction $[14,15]$, which was later attributed to its interaction with SAP30 of the repressor complex [16]. Subsequent studies demonstrated that the NSs protein is multifunctional by (i) acting as a general inhibitor of transcription by sequestering p44 and XPB [17], causing degradation of p62 [18] as well as of the other TFIIH subunits like p52, p34 and cdk7 [17]; (ii) promoting the degradation of PKR [19,20], (iii) modifying gene expression to impair the hosts coagulation cascade [21] and (iv) interacting with gamma satellite pericentromeric sequences, provoking abnormal nuclei during cell division, a function of NSs possibly responsible for RVFV-mediated teratogenesis [22]. In addition, NSs was shown to be responsible for cell cycle arrest at either G0/G1 or $S$ phase, as well as DNA damage response via the ATM protease $[23,24]$. These extensive studies have demonstrated that the NSs protein is the primary virulence factor of the virus and thereby revealed the molecular basis of the avirulent phenotype of Clone 13 . The Clone 13 virus was shown to be highly effective and safe in gestating sheep [25] and calves [26] and was marketed in 2010 by the Onderstepoort Biological Products company in South Africa.

Despite the high safety profile of the Clone 13 virus, efforts are continuing to create vaccines with an even stronger safety signature. To this end, scientists of Institut Pasteur combined the attenuating mutations on the L and M segments of MP-12 with the $\mathrm{S}$ segment of the Clone 13 virus. The resulting reassortant virus, named R566, contains attenuating mutations on each of the three genome segments [27].

In an alternative strategy to develop a vaccine that optimally combines efficacy and safety, a novel vaccine based on a nonspreading RVFV, named NSR-Gn, was recently developed at CVI-WUR [28]. NSR-Gn particles are capable of infecting cells of the vaccinated animal, thereby triggering innate and adaptive immune responsive very similar to those elicited by live-attenuated vaccine viruses. The particles are however optimally safe, since they are incapable of producing progeny virions, due to the absence of the $\mathrm{M}$ genome segment. The NSR-Gn vaccine was recently demonstrated to confer sterile immunity in lambs after a single vaccination [28]. In the current study, the vaccine efficacies of R566 and NSR-Gn were compared, using Clone 13 vaccination as a control for optimal efficacy.

\section{Materials and methods}

\subsection{Ethics statement}

All animal experiments were conducted in accordance with the Dutch Law on Animal Experiments (Wod, ID number BWBR0003081) and approved by the Animal Ethics Committee of CVI-Lelystad. To minimize suffering of the animals during our vaccination challenge experiment, lambs were humanely euthanized when they could no longer be stimulated to drink, feed or stand.

\subsection{Preparation of the vaccines}

The Clone 13 [13] and the NSR-Gn [28] vaccines were previously reported in literature. The R566 vaccine virus was created as follows: Vero cells were grown as described [29] and co-infected with MP-12 and Clone 13 at a multiplicity of infection of 1 and 0.1 , respectively. Viruses released in the culture medium were collected at $48 \mathrm{~h}$ post infection when a complete cytopathic effect was observed as described [30]. The viruses were titrated by plaque assay using the standard method described earlier [31]. Plaques were picked, amplified in Vero cells and screened for NSs expression by immunostaining with NSs-specific antibodies [17]. The origins of the L, M and S segments were determined by RTPCR amplification and sequencing as described [30]. Each selected reassortant was sub-cloned three times by plaque assay and the sequences verified at the first and third cycle.

The R566 and Clone 13 vaccine strains were cultured on Vero cells grown in $490 \mathrm{~cm}^{2}$ roller bottles. The culture medium consisted of a combination of Glasgow's and Eagles modified minimal essential medium (MEM) supplemented with fetal bovine serum and antibiotics. Vaccines were diluted in culture medium to achieve titers appropriate for vaccination.

\subsection{Preparation of the challenge virus}

The molecularly cloned 35/74 (rec35/74) virus was derived from the sequence of strain 35/74 and was titrated on baby hamster kidney (BHK) cells as tissue culture infective dose $50\left(\mathrm{TCID}_{50}\right)$ using the Spearman-Kärber algorithm [32,33]. The virus was handled under biosafety level-3 laboratory conditions in class-III biosafety cabinets.

\subsection{Vaccination and challenge}

Thirty-two lambs of the Romane (INRA 401) breed, 12-14 weeks of age at the moment of vaccination were purchased from Institut National de la Recherche Agronomique (INRA, Nouzilly, France). Lambs were randomized according to gender and age into 4 groups of 8 individuals each and submitted to general health inspection before the start of the study. The Clone 13 vaccine was administered subcutaneously in the right axilla at a dose of $10^{5} \mathrm{pfu}$ in a volume of $1 \mathrm{ml}$. The R566 vaccine was administered subcutaneously in the right axilla with a dose of $10^{6} \mathrm{pfu}$ in a volume of $2 \mathrm{ml}$. The NSR-Gn vaccine was administered via the intramuscular route (neck muscle) at a dose of $10^{6} \mathrm{TCID}_{50}$ in a volume of $1 \mathrm{ml}$. Control lambs were inoculated with $2 \mathrm{ml}$ phosphate buffered saline (PBS, GIBCO $^{\mathrm{TM}}$, Carlsbad, CA, USA) subcutaneously in the right axilla and $1 \mathrm{ml}$ of PBS in the neck muscle.

Three weeks after vaccination, all lambs were sedated by intramuscular administration of medetomidine ( $40 \mu \mathrm{g} / \mathrm{kg}$ medetomidine hydrochloride, Sedator, Eurovet, The Netherlands) and subsequently challenged by administrating $1 \mathrm{ml}$ culture medium containing $10^{5} \mathrm{TCID}_{50}$ of molecularly cloned RVFV strain 35/74 in the vena jugularis. The rescue of the challenge virus was previously reported [34]. For vaccination and challenge, 18 gauge, $25 \mathrm{~mm}$ needles were used. Blood samples for the preparation of sera were collected starting on day 6 before vaccination (DPV -6 ), on the day of vaccination (DPV 0) and subsequently every week until the end of the experiment. EDTA blood samples were collected on DPV -6, 0 and subsequently daily from DPV 21 (the day of challenge) to DPV 32, and on DPV 35 and 42. Body weights were determined on DPV -6 and weekly starting on DPV 0 . Rectal body temperatures were determined daily. The lambs that survived the challenge were euthanized 3 weeks after challenge (DPV 42) by intravenous administration of $50 \mathrm{mg} / \mathrm{kg}$ sodium pentobarbital (Euthasol ${ }^{\circledR}$, ASTfarma, 



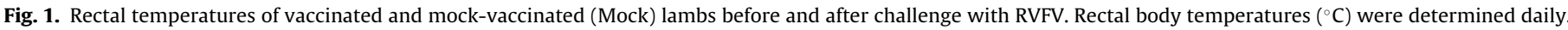

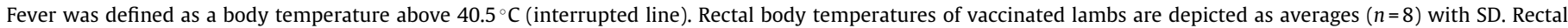

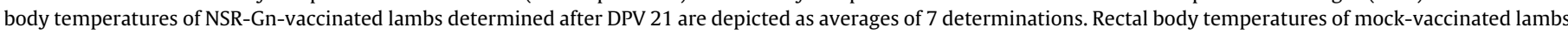
determined after DPV 25 and 27 are depicted as averages of 6 and 5 measurements, respectively, since lambs from this group died on these days.

The Netherlands) and subsequent exsanguination. At necropsy, spleen and liver were collected and stored at $-80^{\circ} \mathrm{C}$.

\subsection{Diagnostic assays}

Quantitative real-time PCR (qRT-PCR), virus isolation, virus neutralization tests and ELISAs were performed as described [35]. Briefly, RNA isolated from plasma was used for quantitative Taqman qRT-PCR. RNA was isolated using the QuickGene DNA tissue kit S (DT-S, Fuji Photo Film Europe GmbH, Dusseldorf, Germany) following the manufacturers' instructions with modifications [35]. The LightCycler RNA Amplification Kit HybProbe (Roche, Almere, The Netherlands) was used and primers, probes and cycling conditions were used as described previously [36].

For virus isolation, BHK cells were incubated with plasma samples diluted 1:1 in culture medium with appropriate supplements, including heparin to prevent clotting of the plasma. After $1 \mathrm{~h}$ incubation, the inocula were replaced with fresh culture medium. After five days, the plates were scored for cytopathic effect.

Antibody responses were analyzed using the commercial ID Screen ${ }^{\circledR}$ Rift Valley Fever Competition ELISA (ID-VET, Montpellier, France), which detects antibodies against the N protein of RVFV.

Virus neutralization tests were performed by incubating $\sim 200$ $\mathrm{TCID}_{50}$ of challenge virus with twofold serial dilutions of sera in 96well plates. After $2.5 \mathrm{~h}$ incubation at room temperature, $40,000 \mathrm{BHK}$ cells were added per well. After $4-5$ days incubation at $37^{\circ} \mathrm{C}$, the cultures were scored for cytopathic effect. Fifty percent end point titers were calculated using the Spearman-Kärber algorithm.

\subsection{Immunohistochemistry}

Organ samples for histopathology were fixed in $10 \%$ phosphatebuffered formalin for a minimum of $48 \mathrm{~h}$ before routine processing into paraffin. Paraffin blocks were cut into $4 \mu \mathrm{m}$ sections, collected on aminopropyltriethoxysilane-coated glass slides and dried for at least 48 -h in a $37^{\circ} \mathrm{C}$ incubator. Sections were deparaffinized in xylene and rehydrated in graded alcohols while endogenous peroxidase activity was blocked in methanol/ $\mathrm{H}_{2} \mathrm{O}_{2}$. Pretreatment consisted of $15 \mathrm{~min}$ autoclaving at $121^{\circ} \mathrm{C}$ in citrate buffer $(\mathrm{pH}$ 6.0). After cooling down, sections were incubated for $60 \mathrm{~min}$ with the monoclonal antibody 4-D4, which is directed against the Gn protein of RVFV (kindly provided by Dr. Connie Schmaljohn, USAMRIID) [37]. Mouse Envision horseradish peroxidase (Dakopatts, Denmark) was used as the secondary antibody. Peroxidase activity was detected using a diaminobenzidine substrate.

\section{Results}

\subsection{Creation of $R 566$}

Vero cells were co-infected with MP-12 and Clone 13 at a multiplicity of infection of 1 and 0.1 , respectively. Viruses released in the culture medium were collected at $48 \mathrm{~h}$ post infection when a complete cytopathic effect was observed. The viral yield was then plaque purified and a first screening was performed on the basis of the ability or inability to express NSs which was evaluated by immunostaining using NSs-specific antibodies as described [17]. The origins of the L, M and S segments were determined by RT-PCR amplification and sequencing as described [30]. The eight expected genotypes were found, some of them being more frequent than others. Three cycles of plaque purification were performed with reassortants possessing the $S$ segment of Clone 13. Full genome sequencing confirmed that Reassortant 566 (R566) combines the $\mathrm{L}$ and M segments of MP-12 with the S segment of Clone 13, and thereby contains attenuating mutations on each genome segment. Virus stocks of R566 were prepared at a low multiplicity of infection $10^{-3} \mathrm{pfu}$ per cell, collected $72 \mathrm{~h}$ post infected and stored at $-80^{\circ} \mathrm{C}$. 

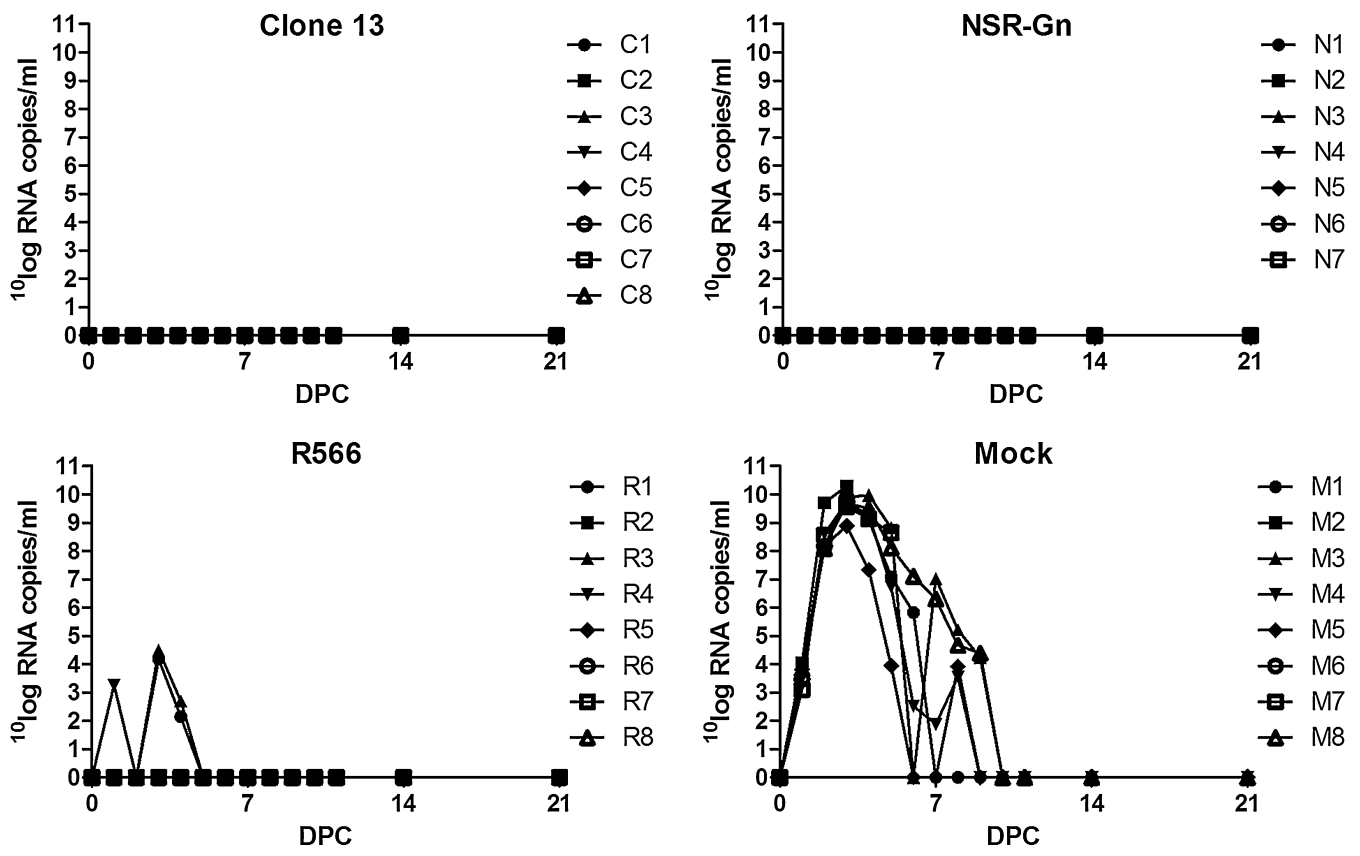

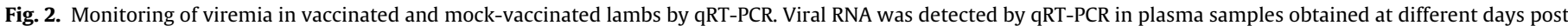
challenge (DPC) with RVFV.

\subsection{Vaccination and challenge}

After one-week acclimatization, lambs were vaccinated with a dose of $10^{6} \mathrm{TCID}_{50}$ of NSR-Gn, $10^{6}$ pfu of R566 or $10^{5}$ pfu of Clone 13. The R566 and Clone 13 vaccines were administered via subcutaneous route, whereas the NSR-Gn vaccine was administered via intramuscular route.

One animal in the control group (animal code: M2) displayed elevated body temperatures from 17 days post vaccination (DPV), and most likely suffered from a pneumonia. None of the other animals displayed elevated body temperatures or clinical signs before challenge infection. Unfortunately, one of the NSR-Gn vaccinated lambs died after administration of anesthetics. Autopsy of this animal demonstrated pulmonary congestion and edema, suggesting that the animal died of shock.

After challenge infection, all unvaccinated lambs developed high fever, which peaked at two days post challenge (DPC) with an average temperature of almost $42^{\circ} \mathrm{C}$ (Fig. 1). Three lambs from this group did not survive the infection. The first lamb to succumb on DPC 3 was lamb M2. This lamb already suffered from an underlying condition, which is believed to have exacerbated the clinical manifestation. Additional fatalities occurred on DPC 4 (M6) and DPC
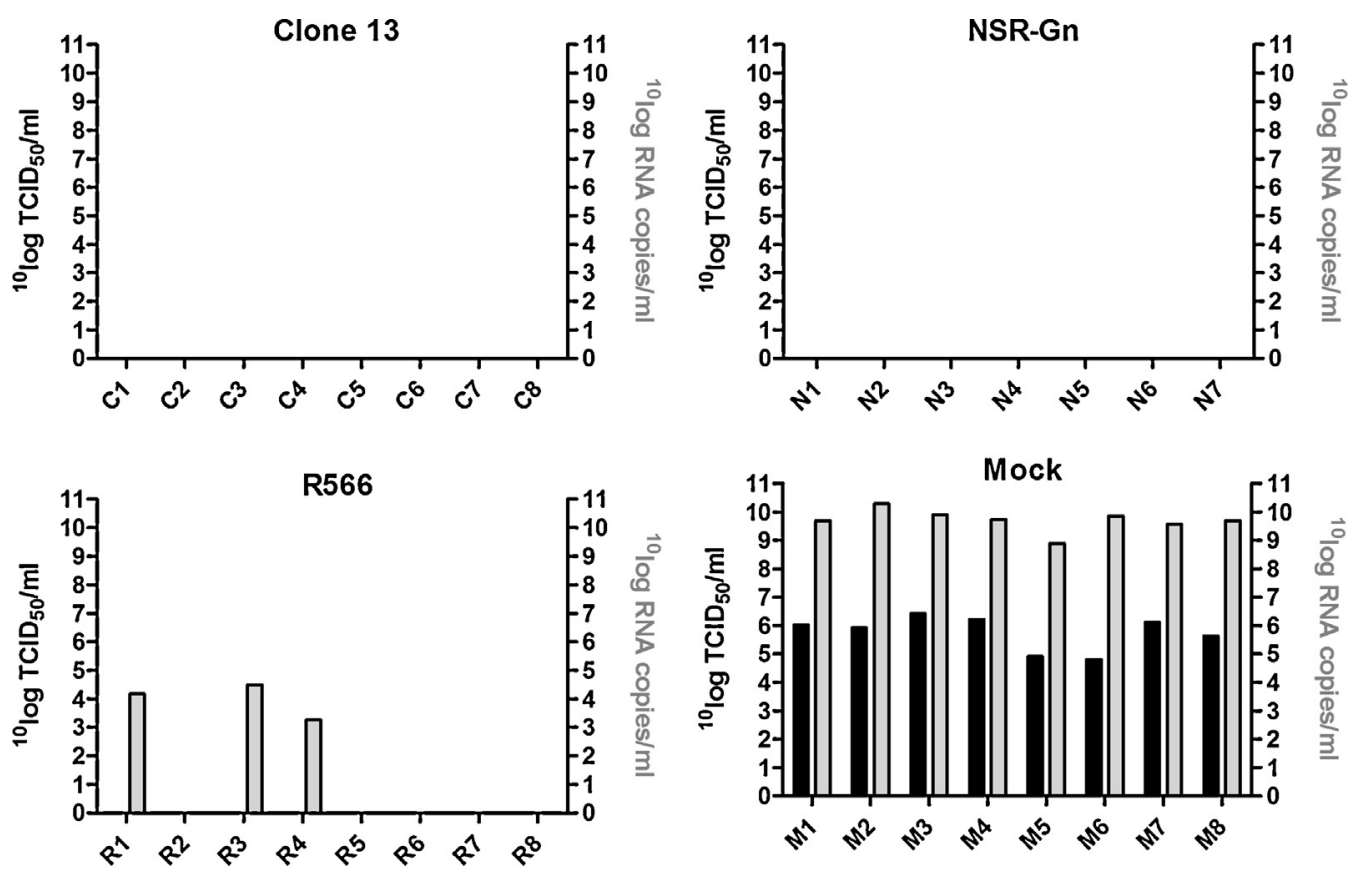

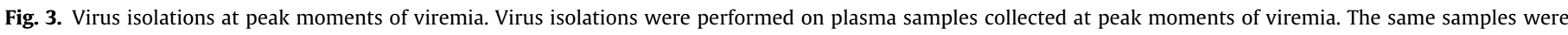
analyzed by qRT-PCR. Results from virus isolations and qRT-PCR analysis are depicted in black and gray, respectively. 
6 (M7). Post mortem examination of lamb M2 revealed a catarrhal bronchopneumonia involving both apical lobes and part of the middle lobes. The liver was swollen and displayed a patchy pattern of pale and dark areas. Edema and hemorrhages were observed in the mesenterium at the junction with the intestines. A large volume of hemorrhagic fluid was present in the abdominal cavity. Autopsy of lamb M6 revealed a severely swollen liver with yellowish color and friable consistency. Icterus was also noted. The abdominal cavity contained a large volume of slightly hemorrhagic fluid. Pulmonary edema was also noted. Lamb M7, which died on DPC 6, revealed signs of shock. Pulmonary edema and icterus were noted and the peritoneum, splenic capsule, pleura and heart revealed many petechiae. The liver was severely swollen, yellowish in color and had a friable consistency. Hyperaemia and congestion was noted in the small intestines. The large intestines contained hemorrhagic contents.

Vaccinated lambs did not develop fever, with the exception of one lamb that was vaccinated with Clone 13. This lamb (C8) developed fever on DPCs 8 and 9 (data not shown). qRT-PCR analyses did not reveal viral RNA in the plasma of this lamb at these time points, suggesting that fever was not caused by the challenge virus. None of the vaccinated lambs developed any clinical signs during the study period.

To monitor viremia, plasma samples were first analyzed by qRTPCR and selected plasma samples were used for virus isolation. High levels of viral RNA were detected by qRT-PCR on plasma samples collected from mock-vaccinated animals (Fig. 2). No challenge virus RNA was detected by qRT-PCR in any of the samples collected from lambs vaccinated with either Clone 13 or NSR-Gn. In contrast, low levels of challenge virus RNA were detected in plasma samples from three R566-vaccinated lambs on DPC 1 (R4) and DPC 3 (R1 and R3, Fig. 2) and two of these lambs (R1 and R3) displayed elevated body temperatures $\left(40.4-40.5^{\circ} \mathrm{C}\right.$ ) on DPC 3 and 4 (data not shown).

Virus isolations were performed with samples collected at the moments of peak viremia, as determined by qRT-PCR. These analyses demonstrated a $10^{3}-10^{4}$-fold difference in sensitivity between virus isolation and qRT-PCR (Fig. 3). Virus was readily isolated from

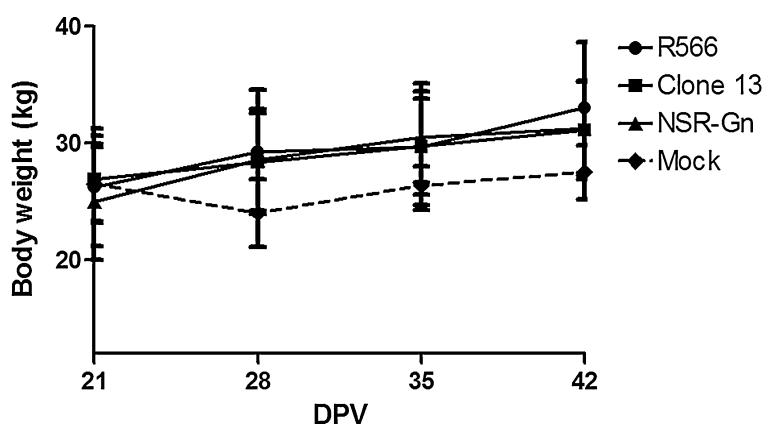

Fig. 4. Body weights of mock-vaccinated and vaccinated lambs after challenge infection. The challenge infection was performed at 21 days post vaccination (DPV). The average body weight of mock-vaccinated lambs determined at DPV 28 results from 5 measurements, respectively, since three lambs from this group died before this day. Body weights of NSR-Gn-vaccinated lambs are averages of 7 measurements. Errors bars represent standard deviations.

plasma samples collected from mock-vaccinated lambs, whereas all plasma samples collected from vaccinated lambs were negative in virus isolation.

The body weights of the lambs were determined weekly. Only the animals in the mock-vaccinated group lost weight in the first week after challenge infection. Surviving lambs from this group gradually gained weight until the end of the experiment (Fig. 4).

At necropsy or at the end of the experimental period, samples from livers and spleens were collected to determine the presence of viral RNA. The organs of the three mock-vaccinated lambs that succumbed to the infection revealed the highest RNA levels (M2, M6 and M7, Fig. 5). Mock-vaccinated lambs M3, M4 and M8 were also positive for viral RNA in both livers and spleens, whereas the livers from lambs M1 and M5 did not contain detectable levels of viral RNA at the end of the experimental period (Fig. 5). Interestingly, two of the three R566-vaccinated lambs (R1 and R3) that contained low levels of challenge virus RNA in the blood at DPC 3 were positive for viral RNA in the spleens at the end of the experimental period.
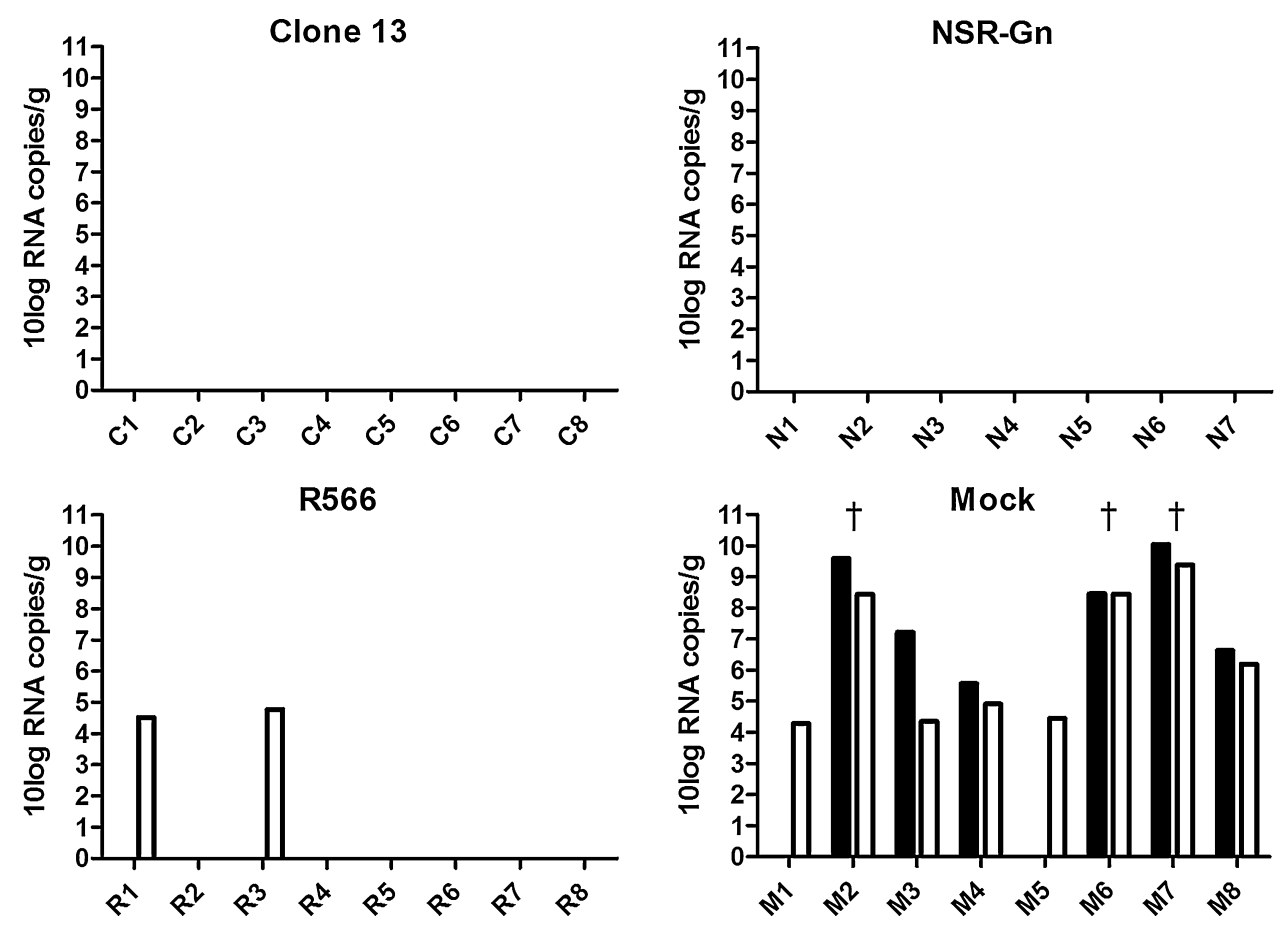


M2, M6 and M7, marked with ${ }^{\dagger}$ ) or from surviving lambs at the end of the experimental period. 


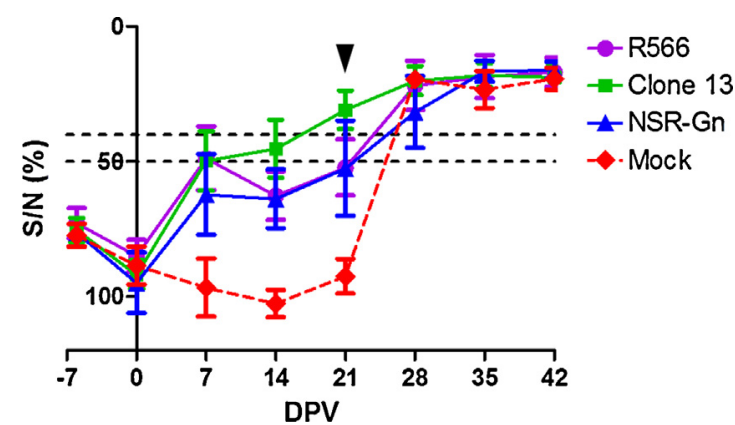

Fig. 6. Detection of anti-N antibodies by ELISA. Sera were obtained 7, 14 and 21 days post vaccination (DPV) and at $0,7,14$ and 21 days post challenge (DPC), corresponding to DPV 21, 28, 35 and 42. Titers are expressed as percentage competition ratio of the optical densities (OD) of the sample and the OD of the negative control $(\% \mathrm{~S} / \mathrm{N})$. All values lower than $40 \%$ are considered positive, between 40 and $50 \%$ are considered doubtful and above $50 \%$ are considered negative. The $40 \%$ and $50 \%$ boundaries are represented by interrupted lines. The moment of challenge infection is indicated by an arrowhead.

Attempts to isolate virus from liver samples of surviving lambs collected after euthanasia were unsuccessful, whereas virus was readily isolated from liver samples collected from lambs that succumbed to the infection (data not shown).

\subsection{Antibody responses}

Whereas all lambs showed rises in anti-N antibody levels between DPV 0 and DPV 7 (Fig. 6), neutralizing antibodies appeared in vaccinated animals about two weeks later (Fig. 7). All lambs vaccinated with Clone 13 or NSR-Gn were positive for neutralizing antibodies on the day of challenge (DPV 21), whereas only 4 of the 8 lambs vaccinated with R566 were positive for these antibodies at this time point (Fig. 7). Of note, all three R566-vaccinated lambs that revealed low levels of viral RNA in the blood after challenge infection were negative for neutralizing antibodies on the day of

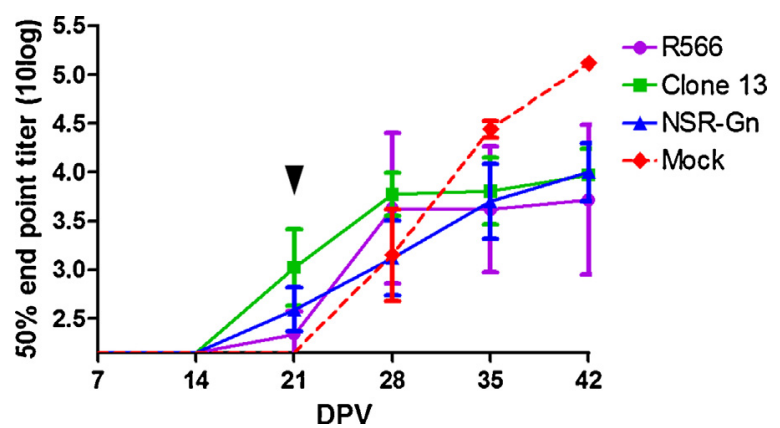

Fig. 7. Results from virus neutralization tests performed with sera obtained from lambs vaccinated with the indicated vaccines or mock-vaccinated lambs at different time points after vaccination and challenge infection. Errors bars represent standard deviations. The $y$-axis crosses at the detection limit of the assay $(y=2.15)$. The moment of challenge infection is indicated with an arrowhead.

challenge, suggesting that the presence of neutralizing antibodies correlates well with the level of protection.

\subsection{Immunohistochemistry}

The organs of the two lambs that died on DPCs 3 and 4 revealed typical signs of RVFV infection, whereas the organs of the lamb that died on 6 DPC (M7) showed more dramatic signs of infection. This lamb died unusually late after the challenge infection and immunohistochemistry revealed exceptional amounts of viral antigen in several target organs. The liver displayed a massive necrosis and immunohistochemistry revealed the presence of RVFV antigen throughout the liver parenchyma only sparing a small rim of periportal hepatocytes (Fig. 8). Interestingly, RVF virus also seemed to target the adrenal gland, as revealed by strong staining for RVFV antigen and necrosis of cortical cells. The mononuclear phagocyte system in the liver (Kuppfer cells) in the red pulp of the spleen and in the medullary and cortical sinuses of the portal lymph node stained intensely for RVFV antigen. Antigen was also detected in the
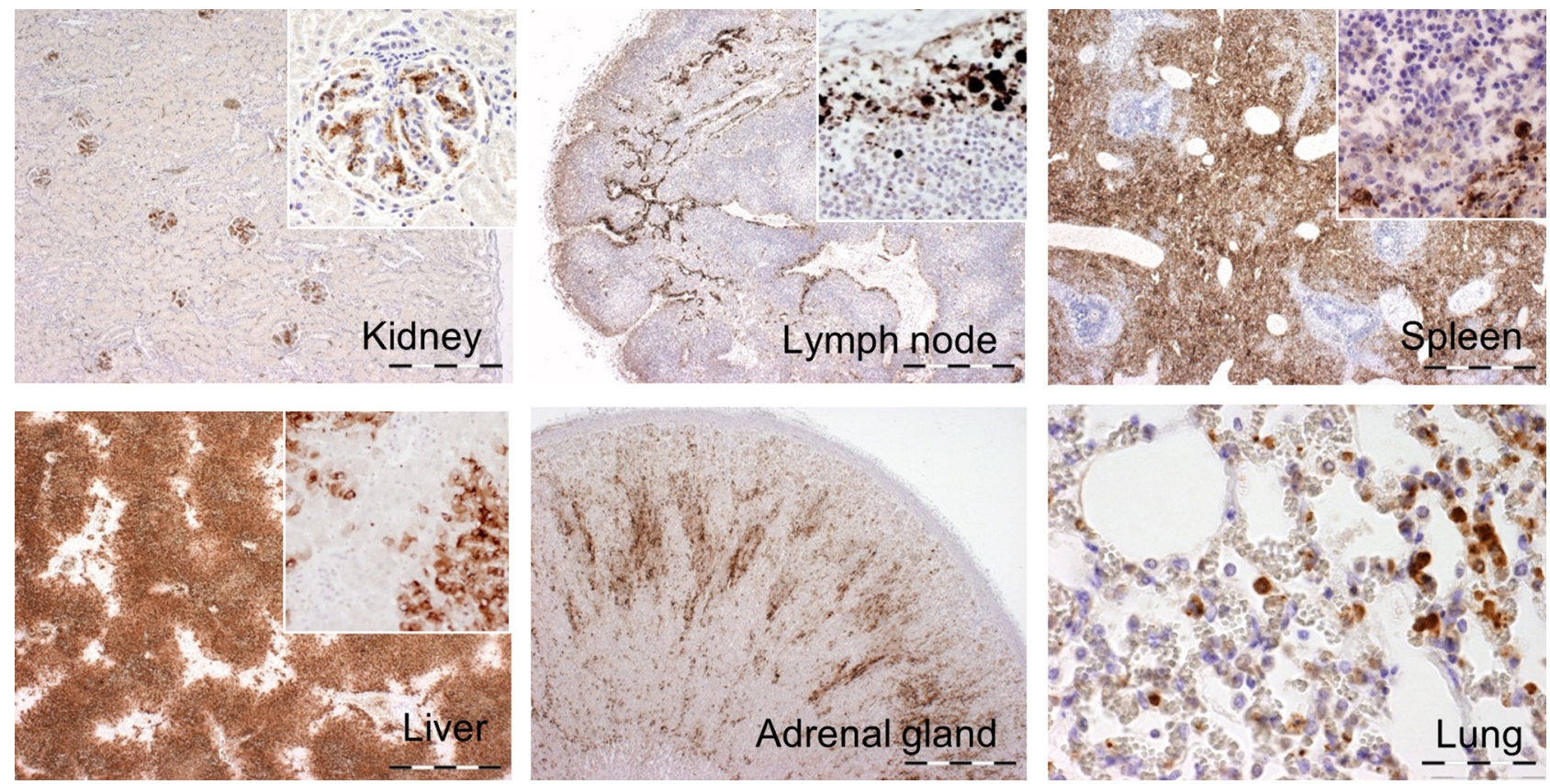

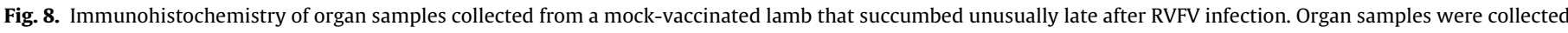

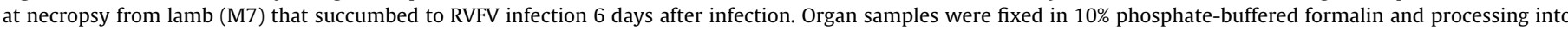

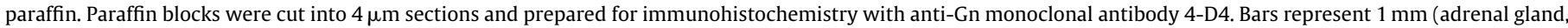

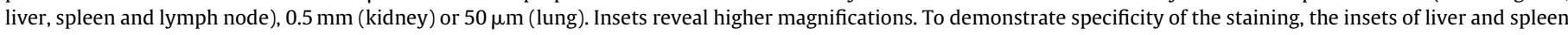
pictures reveal areas were staining was absent. 
intraglomerular mesangial cells in the kidney, in alveolar macrophages in the lung and in macrophages within lymph vessels and blood vessels or capillaries (Fig. 8).

\section{Discussion}

In the past decade, several experimental RVFV vaccines were developed, of which some were already evaluated in the natural target species. It is difficult to compare the results of these animal studies, since no standardized animal models are available. To properly determine which of these vaccine candidates is most effective and thereby warrants further development for commercialization, the vaccines should be compared side by side in animal trials. We here report the results of a comparative trial in which a next-generation vaccine provided by Institut Pasteur, named R566, was compared with the NSR-Gn vaccine, provided by CVI-Lelystad. The Clone 13 vaccine was included as a control for optimal efficacy.

The results of our study suggest that the Clone 13 and NSR-Gn vaccines are more efficacious than the R566 vaccine. Vaccination with Clone 13 or NSR-Gn completely prevented challenge virus viremia, as determined by both virus isolation and the most sensitive qRT-PCR currently available, whereas low levels of challenge virus RNA were detected in the blood of three R566-vaccinated lambs. It is important to note, however, that no challenge virus was isolated from any of the blood samples collected from R566vaccinated lambs. We therefore expect that vaccination with R566 will protect lambs and adult sheep from disease. Nevertheless, it must be considered that a low level of viremia could result in transmission of the virus to the highly susceptible fetus. Given the desire to have one vaccine available to protect ruminants during all physiological stages, including pregnancy, a next-generation vaccine that completely prevents viremia is preferred for registration trials in Europe and other areas that are at risk of future incursions.

We recently reported the results from a dose-titration study with the NSR-Gn vaccine [28]. This previous trial was performed with Texel crossbreed lambs, 12-13 weeks of age at the moment of challenge, whereas in the current study, we made use of Romane lambs (INRA 401 breed), which were 13-15 weeks of age at the moment of challenge. Although these two trials cannot be compared directly, there are some indications that the challenge infections were more severe in the present study. Viremia levels in mock-vaccinated lambs were higher, and three lambs did not survive the infection, whereas one mock-vaccinated lamb died in our previous study [28]. Viral RNA was detected in the livers of three lambs in the previous work, whereas in the present study, almost all organs samples collected from mock-vaccinated lambs were positive for viral RNA. These findings are possibly attributed to a difference in susceptibility of Texel crossbreed and Romane lambs. Despite the more severe manifestation of RVFV infection in the present study, NSR-Gn vaccination was again shown to completely prevent viremia, morbidity and mortality.

\section{Acknowledgements}

We thank Dr. Agnes Billecocq and Dr. Pierre Vialat for their contributions to this work, Dr. Birgit Makoschey (MSD-AH) for useful discussions and critically reading the manuscript and Dr. Connie Schmaljohn (USAMRIID, Fort Detrick, MD) for providing the 4-D4 monoclonal antibody. This work was performed under the umbrella of the Castellum program which is financed by the Dutch Ministry of Economic Affairs.

Conflict of interest statement: J. Kortekaas and R.J.M. Moormann are inventors of WIPO Patent Application WO/2012/039607 "Methods to produce bunyavirus replicon particles". The present work was aimed to select a lead vaccine candidate for production and marketing by MSD-AH.

\section{References}

[1] Bird BH, Nichol ST. Breaking the chain: Rift Valley fever virus control via livestock vaccination. Curr Opin Virol 2012;2:315-23.

[2] Smithburn KC. Rift Valley fever; the neurotropic adaptation of the virus and the experimental use of this modified virus as a vaccine. Br J Exp Pathol 1949;30:1-16

[3] Kamal SA. Pathological studies on postvaccinal reactions of Rift Valley fever in goats. Virol J 2009;6:94.

[4] Botros B, Omar A, Elian K, Mohamed G, Soliman A, Salib A, et al. Adverse response of non-indigenous cattle of European breeds to live attenuated Smithburn Rift Valley fever vaccine. J Med Virol 2006;78:787-91.

[5] Caplen H, Peters CJ, Bishop DH. Mutagen-directed attenuation of Rift Valley fever virus as a method for vaccine development. J Gen Virol 1985;66:2271-7.

[6] Saluzzo JF, Smith JF. Use of reassortant viruses to map attenuating and temperature-sensitive mutations of the Rift Valley fever virus MP-12 vaccine. Vaccine 1990;8:369-75.

[7] Morrill JC, Mebus CA, Peters CJ. Safety of a mutagen-attenuated Rift Valley fever virus vaccine in fetal and neonatal bovids. Am J Vet Res 1997:58:1110-4

[8] Morrill JC, Mebus CA, Peters CJ. Safety and efficacy of a mutagen-attenuated Rift Valley fever virus vaccine in cattle. Am J Vet Res 1997;58:1104-9.

[9] Morrill JC, Laughlin RC, Lokugamage N, Pugh R, Sbrana E, Weise WJ, et al. Safety and immunogenicity of recombinant Rift Valley fever MP-12 vaccine candidates in sheep. Vaccine 2013;31:559-65.

[10] Morrill JC, Jennings GB, Caplen H, Turell MJ, Johnson AJ, Peters CJ. Pathogenicity and immunogenicity of a mutagen-attenuated Rift Valley fever virus immunogen in pregnant ewes. Am J Vet Res 1987;48:1042-7.

[11] Morrill JC, Carpenter L, Taylor D, Ramsburg HH, Quance J, Peters CJ. Further evaluation of a mutagen-attenuated Rift Valley fever vaccine in sheep. Vaccine 1991;9:35-41.

[12] Morrill JC, Laughlin RC, Lokugamage N, Wu J, Pugh R, Kanani P, et al. Immunogenicity of a recombinant Rift Valley fever MP-12-NSm deletion vaccine candidate in calves. Vaccine 2013:31:4988-94.

[13] Muller R, Saluzzo JF, Lopez N, Dreier T, Turell M, Smith J, et al. Characterization of Clone 13, a naturally attenuated avirulent isolate of Rift Valley fever virus which is altered in the small segment. Am J Trop Med Hyg 1995;53:405-11.

[14] Billecocq A, Spiegel M, Vialat P, Kohl A, Weber F, Bouloy M, et al. NSs protein of Rift Valley fever virus blocks interferon production by inhibiting host gene transcription. J Virol 2004;78:9798-806.

[15] Bouloy M, Janzen C, Vialat P, Khun H, Pavlovic J, Huerre M, et al Genetic evidence for an interferon-antagonistic function of rift valley fever virus nonstructural protein NSs. J Virol 2001;75:1371-7.

[16] Le May N, Mansuroglu Z, Leger P, Josse T, Blot G, Billecocq A, et al. A SAP30 complex inhibits IFN-beta expression in Rift Valley fever virus infected cells. PLoS Pathog 2008;4:e13.

[17] Le May N, Dubaele S, Proietti De Santis L, Billecocq A, Bouloy M, Egly JM. TFIIH transcription factor, a target for the Rift Valley hemorrhagic fever virus. Cell 2004; $116: 541-50$

[18] Kalveram B, Lihoradova O, Ikegami T. NSs protein of rift valley fever virus promotes posttranslational downregulation of the TFIIH subunit p62. J Virol 2011:85:6234-43.

[19] Ikegami T, Narayanan K, Won S, Kamitani W, Peters CJ, Makino S. Dual functions of Rift Valley fever virus NSs protein: inhibition of host mRNA transcription and post-transcriptional downregulation of protein kinase PKR. Ann N Y Acad Sci 2009;1171(Suppl. 1):E75-85.

[20] Habjan M, Pichlmair A, Elliott RM, Overby AK, Glatter T, Gstaiger M, et al. NSs protein of rift valley fever virus induces the specific degradation of the doublestranded RNA-dependent protein kinase. J Virol 2009:83:4365-75.

[21] Benferhat R, Josse T, Albaud B, Gentien D, Mansuroglu Z, Marcato V, et al. Large-scale chromatin immunoprecipitation with promoter sequence microarray analysis of the interaction of the NSs protein of Rift Valley fever virus with regulatory DNA regions of the host genome. J Virol 2012;86:11333-44.

[22] Mansuroglu Z, Josse T, Gilleron J, Billecocq A, Leger P, Bouloy M, et al. Nonstructural NSs protein of rift valley fever virus interacts with pericentromeric DNA sequences of the host cell, inducing chromosome cohesion and segregation defects. J Virol 2010;84:928-39.

[23] Austin D, Baer A, Lundberg L, Shafagati N, Schoonmaker A, Narayanan A, et al. p53 Activation following Rift Valley fever virus infection contributes to cell death and viral production. PLoS ONE 2012;7:e36327.

[24] Baer A, Austin D, Narayanan A, Popova T, Kainulainen M, Bailey C, et al. Induction of DNA damage signaling upon Rift Valley fever virus infection results in cell cycle arrest and increased viral replication. J Biol Chem 2012;287:7399-410.

[25] Dungu B, Louw I, Lubisi A, Hunter P, von Teichman BF, Bouloy M. Evaluation of the efficacy and safety of the Rift Valley fever Clone 13 vaccine in sheep. Vaccine 2010;28:4581-7.

[26] von Teichman B, Engelbrecht A, Zulu G, Dungu B, Pardini A, Bouloy M. Safety and efficacy of Rift Valley fever Smithburn and Clone 13 vaccines in calves. Vaccine 2011;29:5771-7.

[27] Bouloy M, Flick R. Reverse genetics technology for Rift Valley fever virus: current and future applications for the development of therapeutics and vaccines. Antiviral Res 2009;84:101-18. 
[28] Oreshkova N, van Keulen L, Kant J, Moormann RJ, Kortekaas J. A single vaccination with an improved nonspreading rift valley Fever virus vaccine provides sterile immunity in lambs. PLOS ONE 2013;8:e77461.

[29] Vialat P, Muller R, Vu TH, Prehaud C, Bouloy M. Mapping of the mutations present in the genome of the Rift Valley fever virus attenuated MP12 strain and their putative role in attenuation. Virus Res 1997;52:43-50.

[30] Vialat P, Billecocq A, Kohl A, Bouloy M. The S segment of rift valley fever phlebovirus (Bunyaviridae) carries determinants for attenuation and virulence in mice. J Virol 2000;74:1538-43.

[31] Billecocq A, Vialat P, Bouloy M. Persistent infection of mammalian cells by Rift Valley fever virus. J Gen Virol 1996;77:3053-62.

[32] Kärber G. Beitrag zur kollektiven Behandlung pharmakologischer Reihenversuche. Arch Exp Path Pharm 1931;162:480-3.

[33] Spearman C. The method of right and wrong cases (constant stimuli) without Gauss's formulae. Br J Psych 1908;2:227-42.
[34] Kortekaas J, Oreshkova N, Cobos-Jimenez V, Vloet RP, Potgieter CA, Moormann RJ. Creation of a nonspreading Rift Valley fever virus. J Virol 2011;85: $12622-30$.

[35] Kortekaas J, Antonis AFG, Kant J, Vloet RPM, Vogel A, Oreshkova N, et al. Efficacy of three candidate Rift Valley fever vaccines in sheep. Vaccine 2012;30: 3423-9.

[36] Drosten C, Gottig S, Schilling S, Asper M, Panning M, Schmitz H, et al. Rapid detection and quantification of RNA of Ebola and Marburg viruses, Lassa virus, Crimean-Congo hemorrhagic fever virus, Rift Valley fever virus, dengue virus, and yellow fever virus by real-time reverse transcription-PCR. J Clin Microbiol 2002:40:2323-30

[37] Keegan K, Collett MS. Use of bacterial expression cloning to define the amino acid sequences of antigenic determinants on the G2 glycoprotein of Rift Valley fever virus. J Virol 1986;58:263-70. 